Review Article

\title{
Study of the Effects of Heating on Organic Matter and Mineral Phases in Limestones
}

\author{
J. May-Crespo (iD, ${ }^{1}$ P. Martínez-Torres, ${ }^{2}$ P. Quintana, ${ }^{3}$ J. J. Alvarado-Gil, ${ }^{3}$ \\ L. Vilca-Quispe, ${ }^{4}$ and N. Camacho ${ }^{5}$ \\ ${ }^{1}$ CONACYT, Research Fellow-El Colegio de Michoacán A.C.,Cerro de Nahuatzen, No. 85,Fracc. Jardines Del Cerro Grande, \\ La Piedad de Cavadas, 59370 Michoacán, Mexico \\ ${ }^{2}$ Institute of Physics and Mathematics, Universidad Michoacana de San Nicolás de Hidalgo, Edificio C-3, Ciudad Universitaria, \\ 58040 Morelia, Michoacán, Mexico \\ ${ }^{3}$ Department of Applied Physics, Cinvestav-Unidad Mérida, Carretera Antigua a Progreso, Km. 6, 97310 Mérida, \\ Yucatán, Mexico \\ ${ }^{4}$ Departamento de Física, Facultad de Ciencias, Universidad Nacional Jorge Basadre Grohmann, Av. Miraflores $s / n$, \\ Tacna 23000, Peru \\ ${ }^{5}$ CONACYT-CIDESI-CENTA, National Center of Aeronautical Technologies, \\ Carretera Estatal 200 Querétaro-Tequisquiapan Km. 23,No. 2254,Localidad Galeras,76270,Parque Aeroespacial Querétaro, \\ Colón, Querétaro, Mexico
}

Correspondence should be addressed to J. May-Crespo; jose.may@colmich.edu.mx

Received 28 July 2021; Revised 22 September 2021; Accepted 23 September 2021; Published 29 October 2021

Academic Editor: Luciano Bachmann

Copyright (c) $2021 \mathrm{~J}$. May-Crespo et al. This is an open access article distributed under the Creative Commons Attribution License, which permits unrestricted use, distribution, and reproduction in any medium, provided the original work is properly cited.

Color-induced changes in stones due to heating can be useful in determining the degree of degradation generated in their components and structure. We evaluate the effect of heating in three types of limestones, useful in building and restoration, corresponding to biomicrite (BC), biosparite (BS), and intramicrite (IM), in the range of temperature from $100^{\circ} \mathrm{C}$ to $600^{\circ} \mathrm{C}$. Our analyses indicate that the strongest changes in reflectance occur in the samples of intramicrite, followed by biomicrite, being biosparite showing the smallest ones. Additionally, IM samples suffer the largest modifications in effective porosity due to the thermal treatment; in contrast, BS and BC samples show smaller temperature-induced alterations associated with smaller changes in reflectance. Moreover, we reveal that most of the thermally induced variations are associated, in this range of temperature, to the dehydroxylation of goethite that transforms into hematite, as well as by the burning and partial release of the organic matter present in the rock. Colorimetry analyses show that the sequence of thermally induced changes can be followed by the evolution of the three coordinates, $L^{*}$ (lightness), $a^{*}$ (red-green), and $b^{*}$ (yellow-blue), of the CIE $1976 L^{*} a^{*} b^{*}$ space.

\section{Introduction}

Limestone is the most abundant type of rock in southeastern Mexico and constitutes the basis of the building legacy in pre-Columbian, colonial, and modern periods. Particularly, ancient Maya used different types of limestone to develop structures, buildings, and sculptures, as can be observed in numerous Maya archeological zones such as Uxmal and Chichén Itzá. Limestones are also a fundamental part of several historical buildings and monuments, dating from the colonial period. Currently, limestone is used for various purposes in the building industry and particularly in the restoration of historical monuments such as stonework and sculptures [1-3].

Limestones are obtained from extensive quarries, which provide materials with a wide variety of colors, physical properties, microstructure, and chemical composition. The natural color of this type of sedimentary rock reflects the fundamental characteristics of its mineral composition and natural pigments $[4,5]$. Limestones are mostly composed of 
calcium carbonate $\left(\mathrm{CaCO}_{3}\right)$, with an appearance, which generally ranges from white, passing through a great variety of colors. These colors are related to the roughness of the surface of the stone, to the content of organic matter, and to the presence of quartz, feldspar, and clay minerals, among many other factors $[4,6]$.

Some limestones used to have a natural ochre color, which is largely attributed to the existence of iron minerals, such as hematite $\left(\mathrm{Fe}_{2} \mathrm{O}_{3}\right)$ and goethite $(\alpha-\mathrm{FeOOH})$. Red color is mainly due to their high content of hematite, while the ochre color can be attributed to goethite, and the orange color can be ascribed to the presence of a mixture of mineral oxides. Besides, during the formation process of the stone, organic matter can become trapped, acting as natural pigments, which also contributes to the color of the limestone. The percentage of organic matter is usually less than $1 \%$ wt., where $0.8 \%$ is associated with the gray hue in limestone [6].

In recent years, studies about changes in the physical and chemical properties of rocks as a function of temperature variations have increased, particularly in archeological conservation and construction material engineering $[5,7-11]$. When rocks are subjected to high temperatures, their physical and chemical properties are directly and irreversibly affected, not only from the aesthetic point of view but also become more fragile and prone to lose their integrity and eventual destruction [12-19].

In the specific case of color, the most convenient mode to address the effects of temperature is by studying the variations of the physicochemical properties in a controlled manner. Some works have suggested that most of the color changes are mainly due to mineralogical phase changes; however, the effects of burning the organic matter inside the matrix on the color of the stone can also be remarkable, although those have been less reported in the literature $[14,17,20]$.

The effects of heating on the lithotype have been studied for different ranges of temperatures in sandstone, marble, muds, limestones, granite, chalks, and dolerites, among others. These studies reported mineralogical transformations in the components of the stones, such as calcium carbonate, clays, and iron minerals, as well as in the organic matter $[10-12,14,17,19,20]$.

Most thermally induced changes in the microstructure of the stone can be followed by observing the evolution of the color and optical properties of its surface. Optical techniques are simple and reliable and when combined with structural and microscopic analyses are helpful in the development of methodologies for the fast evaluation and ulterior study of the effects of heating on stones. Particularly, diffuse reflectance spectroscopy has shown to be one of the most important standard techniques to measure the optical properties and color of a great variety of rocks and soils. Diffuse reflectance is an accurate technique that provides color measurements, which can be described in terms of the Munsell system or by the International Commission on Illumination (CIE). Diffuse reflectance has shown to be useful in the identification of iron oxides in natural soils, sediments, carbonated minerals, clays, and organic matter [21-26]. Color changes associated with the degree of roughness for different lithotypes have been reported [27]. Additionally, the reflectance spectra of rocks with high amounts of carbonated minerals containing calcite, aragonite, dolomite [24], and volcanic ash [28] have been reported. Some studies have been performed in the characterization and identification of mineral goethite from natural soils and sediments [29] as well as the measurements of quantification of the color of natural ochres [30].

One of the greatest challenges is the identification of the damage to the stones made by heating using simple noncontact and noninvasive techniques, which can guarantee the lowest degree of manipulation of the rocks and can be used as an in situ measurement.

In this study, we study the influence of heating on the optical properties and color changes in three types of limestones. The range of thermal treatments were from $100^{\circ} \mathrm{C}$ to $600^{\circ} \mathrm{C}$, in which the major damage of the structure can be avoided. The analyses of the optical properties were performed by diffuse reflectance in the visible region of the electromagnetic spectrum. The changes in color are analyzed and described in terms of the International Commission on Illumination CIE $1976 L^{*} a^{*} b^{*}$ color space. To get a deeper understanding of the transformations occurring in the samples and how they are correlated with our optical spectroscopy results, analyses of porosity, X-ray diffraction, as well as microscopy and thermogravimetry were performed. Additionally, XRD and EDXs were used to identify the mineral phases and their evolution with temperature.

\section{Materials and Methods}

2.1. Preparation of Samples. The analyses were performed in three different lithotypes obtained from quarries of the Peninsula of Yucatan (Figure 1). The samples were identified as biomicrite (BC), biosparite (BS), and intramicrite (IM), as shown in Figure S1. They are mostly composed of calcite matrixes. BC and BS correspond to micritic calcite and sparite calcite, respectively, both having high content of microfossil such as ooids covered with a layer of Fe oxides. IM constituted of micritic calcite and intraclasts particles with zones of iron minerals.

The samples were cut in $1.5 \times 1.5 \times 1 \mathrm{~cm}^{3}$ using a precision saw (Buehler Isomet) with a diamond-coated disk (Buehler). After that, they were polished with sandpaper, beginning with a large grain size (220) and ending with a fine grain (2000), and finally cleaned with distilled water for $2 \mathrm{~min}$ in an ultrasonic bath. Thermal treatments were applied during $2 \mathrm{~h}$, for temperatures from $100^{\circ} \mathrm{C}$ to $600^{\circ} \mathrm{C}$ in steps of $100^{\circ} \mathrm{C}$, in air atmosphere using a conventional furnace. After the thermal treatment, the samples were cooled down gradually until reaching room temperature.

\subsection{Characterization}

2.2.1. X-Ray Diffraction (XRD). Mineralogical characterization of the rocks was carried out in a Siemens D-5000 diffractometer operated at $34 \mathrm{kV}$ and $25 \mathrm{~mA}$, with a Bragg-Brentano geometry, using monochromatic $\mathrm{CuK} \alpha$ radiation $(\lambda=1.5418 \AA)$. XRD patterns were registered in the 


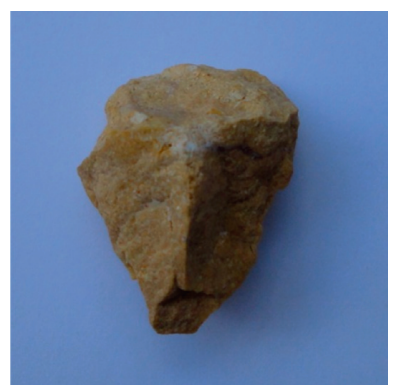

$\mathrm{BC}$

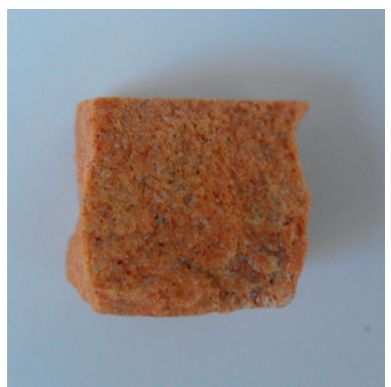

BS

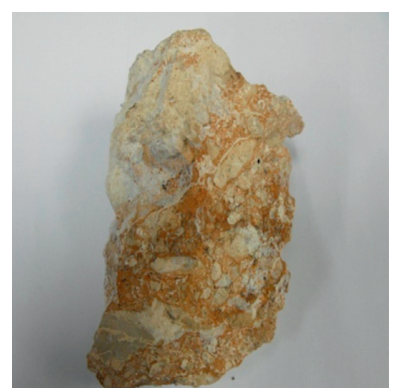

IM

FIGURE 1: Image of the studied raw lithotypes.

range of $10^{\circ} \leq 2 \theta \leq 60^{\circ}$ with a step size of $0.02^{\circ}$ and a step time of $6 \mathrm{~s}$. Additionally, calcium carbonate was dissolved with a $5 \% \mathrm{v} / \mathrm{v} \mathrm{HCl}$ solution to identify the presence of other minerals which were labeled as PAD (powders obtained after the dissolution).

\subsubsection{Energy Dispersive X-Ray Spectroscopy (EDXs).} Chemical analysis of untreated rocks and PAD was performed using energy dispersive X-ray spectroscopy on a scanning electron microscope Philips XL30 operated at $25 \mathrm{kV}$.

\subsubsection{Thermogravimetric Analysis (TGA).}

Thermogravimetric analysis (TGA) was performed using a Discovery TGA (TA instruments) for the three types of limestones as powders for untreated and PAD samples. The sample holder was heated from 50 to $900^{\circ} \mathrm{C}$ with a heating rate of $10^{\circ} \mathrm{C} / \mathrm{min}$ in an inert $\mathrm{N}_{2}$ atmosphere. The derivative of the thermogravimetric curves (DTG) helps to determine the temperature at which the maximum rate of thermal decomposition is reached.

2.2.4. Diffuse Reflectance Spectroscopy. Optical properties and color measurements of the samples as a function of the thermal treatment were carried out by diffuse reflectance spectroscopy. The samples were illuminated with a deuterium-halogen light source (AvaLight DH-S-BAL) using an optical fiber; the light reflected were collected with an integrating sphere (Labsphere USRS-99-010) and sent into the spectrometer using an optical fiber (AvaSpec-2048). The reflectance spectra were recorded from $380 \mathrm{~nm}$ to $1000 \mathrm{~nm}$. The reference sample was an Ocean Optics diffuse reflectance standard (WS-1-SL). The measurements were performed in such a way that the samples were always situated in the same position, using a silicone mold. The color was measured in an area of approximately $50 \mathrm{~mm}^{2}$, and the measurements were repeated three times for each sample. The color variation was described in terms of $L^{*} a^{*} b^{*}$ space color (CIE, 1976), where the value of $L^{*}$ represents lightness ( $L^{*}=0$ : black, and $L^{*}=100$ : white), and $a^{*}$ and $b^{*}$ represent chromaticity $\left(+a^{*}=\right.$ red, $-a^{*}=$ green; $+b^{*}=$ yellow, and $-b^{*}=$ blue) [21].
2.2.5. Effective Porosity. The percentage of effective porosity as a function of the thermal treatment was determined for the three lithotypes using the saturation technique according to the International Society for Rock Mechanics [31]. To perform these experiments, three sets of cubic samples for each type of rock were prepared and subjected to thermal treatment as described in Section 2.2.1. The effective porosity $(\varepsilon)$ was found applying the formula [12]:

$$
\varepsilon=\frac{V_{\text {pore }}}{V_{\text {bulk }}},
$$

with

$$
\begin{gathered}
V_{\text {pore }}=\frac{\left(M_{\text {surf_dr } y}-M_{d r y}\right)}{\rho_{\text {water }}}, \\
V_{\text {bulk }}=\frac{\left(M_{\text {sat }}-M_{\text {surf_dr } y}\right)}{\rho_{\text {water }}},
\end{gathered}
$$

where $M_{\text {sat }}$ is the saturated submerged weight that is obtained by measuring the weight after immersing the samples in a distilled waterbath for a period of $48 \mathrm{~h} . M_{\text {surf_dry }}$ is the saturated surface dry weight measured outside the water and corresponds to the case in which the surface of the saturated submerged sample is dried with a moist cloth. $M_{d r}$ is the dry weight of samples and was determined after drying the sample at a temperature of $105^{\circ} \mathrm{C}$ for a period of $24 \mathrm{~h}$. $\rho_{\text {water }}$ is the density of water. The weight of each sample in each lithotype was measured three times. Based on the results of all the measurements for each type of sample, the mean and the standard deviation were calculated, providing the uncertainty values, as shown in Figure 2. It was observed that the standard deviation due to the repetition of the measurements for the same sample did not exceed $0.02 \%$ in all cases; therefore, the most significant contribution to the uncertainty in the measurement of the weight in different samples of the same type is due to the differences among those samples because of the inhomogeneity of the rocks from which the individual samples were obtained.

2.2.6. Organic Matter. To determine the initial content of organic matter of the natural samples, $5 \mathrm{~g}$ of each type of limestone was ground in an agate mortar and deposited into an alumina crucible. After that, it was analyzed according to 


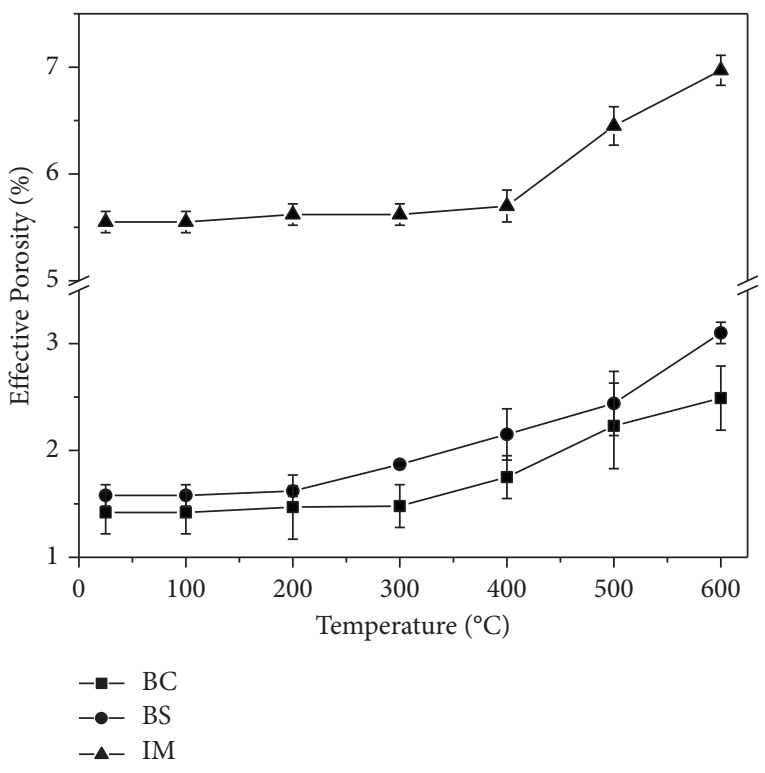

FIGURE 2: Increase of effective porosity as a function of the thermal treatment temperature for each lithotype.

reference [32] obtaining $1.80 \%$ for IM and $0.52 \%$ for BC and BS.

\section{Results}

3.1. Chemical Composition Analysis. EDXs analysis of the surface of the stones without thermal treatment shows that the chemical composition can be mainly attributed to $\mathrm{CaCO}_{3}$. Only IM rocks present some variations, such as high content of $\mathrm{Si}$ and $\mathrm{Al}$, associated with the amount of clay materials. Additionally, EDXs analysis was performed on the PAD powders obtained after the elimination of carbonate also without thermal treatment. Table 1 provides the elements clearly identified in the analysis, in which trace elements are not displayed. In this case, BC-PAD and BS-PAD samples exhibit a higher amount of Fe in comparison to IMPAD; besides, IM-PAD shows a higher percentage of $\mathrm{Al}, \mathrm{Si}$, $\mathrm{Mg}, \mathrm{K}$, and $\mathrm{Ca}$, being only this type of rock that exhibited traces of $\mathrm{Ti}$.

3.2. Mineral Phases. The crystalline structures on the surface of the rock were studied by XRD for all the thermally treated samples up to $600^{\circ} \mathrm{C}$ (data not shown). The obtained results agree with previous studies which indicate that above $600^{\circ} \mathrm{C}$, calcite begins to release $\mathrm{CO}_{2}$ forming calcium oxide [33]. Additionally, minor diffraction peaks corresponding to $\alpha$-quartz $\left(\mathrm{SiO}_{2}\right)$ were detected.

Besides, by removing the calcium carbonate matrix, it was possible to determine the rest of the nondissolved minerals after using the acid medium. XRD patterns of those powders showed the presence of goethite, hematite, as well as quartz, clays such as tosudite $\left((\mathrm{K}, \mathrm{Ca}) \mathrm{O}_{8} \mathrm{Al}_{6}(\mathrm{Si}, \mathrm{Al})_{8} \mathrm{O}_{20}(\mathrm{OH})_{10} 4 \mathrm{H}_{2} \mathrm{O}\right)$ and kaolinite $\left(\mathrm{Al}_{2} \mathrm{Si}_{2} \mathrm{O}_{5}(\mathrm{OH})_{4}\right)$ at $25^{\circ} \mathrm{C}$ (Figure 3$)$. High amounts of hematite and goethite are present in BS and BC samples; however, IM presents a high proportion of tosudite and quartz, but a low content of both aforementioned iron minerals (Figure 3(c)). The diffraction patterns of $\mathrm{PAD}$ samples treated at $200^{\circ} \mathrm{C}$ are similar to the nontreated ones at $25^{\circ} \mathrm{C}$. In contrast, when the thermal treatment rises to $300^{\circ} \mathrm{C}$, a significant change is observed, and the main peak of goethite disappears, while hematite peak increases. This is due to the transformation of goethite to hematite around $230^{\circ} \mathrm{C}$ because of the loss of hydroxyl ion $\left(\mathrm{OH}^{-}\right)$ $[29,34]$. These changes are especially noticeable for the samples of $\mathrm{BC}$ and $\mathrm{BS}$. The process of dehydration of goethite can be described in the following simple reaction:

$$
2 \mathrm{FeO}(\mathrm{OH}) \longrightarrow \mathrm{Fe}_{2} \mathrm{O}_{3}+\mathrm{H}_{2} \mathrm{O}
$$

Finally, at $600^{\circ} \mathrm{C}$, the transformation from goethite to hematite is complete. Moreover, the main diffraction peaks associated with tosudite and quartz show that these crystalline phases are thermally stable for all heating treatments. In contrast, the main broad peak of kaolinite at $12^{\circ}(2 \theta)$ begins to disappear around $500^{\circ} \mathrm{C}[11,14]$.

3.3. Thermogravimetry Measurements. TGA and DTG (obtained from the derivate of TGA curve) thermograms show a single-step decomposition for the three types of natural limestones (Figure 4) that occur in the range from 600 to $800^{\circ} \mathrm{C}$ and mainly attributed to the loss of $\mathrm{CO}_{2}$ close to $750^{\circ} \mathrm{C}$, with a total mass loss of around $44 \%$ [33].

The thermogravimetric analysis applied to BC-PAD, BSPAD, and IM-PAD (Figure 5) show the degradation during the heating process, where three stages can be identified. In the first one $\left(50-150^{\circ} \mathrm{C}\right)$, the fall in weight around $100^{\circ} \mathrm{C}$ is related to water release. At the second stage $\left(150-350^{\circ} \mathrm{C}\right)$, a minimum in the derivative of the weight loss occurs at around $275^{\circ} \mathrm{C}$, which can be associated with the dehydroxylation of goethite and its transformation into hematite [34]. This transformation in the second stage is not observed in IM-PAD due to the high content of tosudite and quartz. Finally, a third stage (above $350^{\circ} \mathrm{C}$ ), in which around $450^{\circ} \mathrm{C}$ a shoulder appears, corresponds to the elimination of the rest of the organic matter, the loss of water absorbed in clays, and the removal of the hydroxyl groups located in the interlayer between kaolinite and tosudite [35].

3.4. Diffuse Reflectance Characterization. Reflectance spectra for all types of the analyzed limestones show a similar behavior in general terms, having all of them high reflectance under $450 \mathrm{~nm}$ and above $650 \mathrm{~nm}$ with a wide minimum around $540 \mathrm{~nm}$, as shown in Figure 6. It is also clear in the spectra for all the limestones that the size of the minimum decreases as the temperature of the thermal treatment evolves.

Reflectance spectra of rocks have been reported previously, in which, when the main component is calcium carbonate, the spectra are nearly flat in the visible region with a slight monotonic decrease under $400 \mathrm{~nm}$ [13]. Similar reflectance spectra for natural Fe oxides and hydroxides, mainly of hematite and goethite, show that it is possible to single-out the reflectance of each of these minerals using diffuse reflectance spectroscopy $[13,36]$. The difference with 
TABLE 1: EDXs analysis of untreated PAD minerals.

\begin{tabular}{lcccccccc}
\hline \multirow{2}{*}{ Sample } & \multicolumn{8}{c}{ Element (\% wt.) } \\
& $\mathrm{C}$ & $\mathrm{O}$ & $\mathrm{Fe}$ & $\mathrm{Al}$ & $\mathrm{Si}$ & $\mathrm{Mg}$ & $\mathrm{K}$ & $\mathrm{Ca}$ \\
\hline BC-PAD & 27.6 & 38.4 & 19.8 & 5.1 & 7.3 & 0.9 & 0.4 & 0.4 \\
BS-PAD & 14.4 & 40.0 & 27.8 & 6.7 & 8.7 & 1.0 & 0.4 & 0.4 \\
IM-PAD & 25.2 & 42.8 & 3.0 & 8.9 & 15.7 & 1.6 & 1.6 & 0.8 \\
\hline
\end{tabular}

our results is mainly due to the presence of organic material, whose contribution becomes noticeable when the samples are thermally treated. This effect can be appreciated in Figure S2 that shows the digital images of the samples in the range of thermal treatments, which allows appreciating qualitatively the gradual changes of color followed by darkening as the temperature increases due to the changes of the natural pigments.

Note that for nonthermally treated rocks, the spectra of biomicrite and biosparite (Figure 6) are very similar to those reported by Elias et al. [30] for ochres, due to the presence of hematite and goethite. This result agrees with the petrographic analysis shown in Figure S1 of the supplementary material where both types of rock are composed of microcalcite and ooids, covered with iron materials, mainly consisting of a mixture of goethite and hematite. These findings are also supported by the results of XRD for BS$\mathrm{PAD}$ and BC-PAD of the nontreated limestones (Figure 3). The similarity of the results for limestones $\mathrm{BS}$ and $\mathrm{BC}$ can also be accentuated by the fact that both types of samples have similar effective porosity, and the percentage of organic material is very close (Figure 2).

$\mathrm{BC}$ shows defined bands that can be associated halfway between hematite and goethite. BS rocks present a strong influence of the high hematite content, which appears as a maximum around $765 \mathrm{~nm}$, which can shift when compared to ochre [30]. In contrast, sample IM presents totally different features due to the high content of clay minerals.

The treatment at $100^{\circ} \mathrm{C}$ does not produce important changes in the reflectance spectra of the three types of limestones. However, above $200^{\circ} \mathrm{C}$, thermal treatments produce strong changes that at higher temperature make the spectra smoother for the range of measured wavelengths.

For BS, the thermal treatments produce small changes for wavelengths around $530 \mathrm{~nm}$. In contrast, IM is the most affected by the thermal treatment, specially observed at $600^{\circ} \mathrm{C}$, followed by the sample BC, being the BS sample the least affected.

Our results for the evolution of the reflectance region between $400 \mathrm{~nm}$ and $700 \mathrm{~nm}$ are consistent with the literature, in which it has been shown that the spectra of soils of similar composition are especially sensitive to the changes of the concentration of iron minerals, and it has proved to be an important tool to characterize and identify different types of iron oxides [29].

Considering that the reflectance in the region of the highest wavelength is the most affected by the thermal treatment, the fixed wavelength at $765 \mathrm{~nm}$ will be taken as a reference to determine the variation in this zone. Figure 6(d) shows the evolution of reflectance at $765 \mathrm{~nm}$ as a function of temperature. This wavelength was also selected to determine the relevance of the thermal treatment in this region due to its relationship to the presence of iron oxides [30]. IM sample shows the strongest decay from $75 \%$ to $19 \%$ (about $56 \%$ ), when the sample goes from ambient temperature to $600^{\circ} \mathrm{C}$. In contrast, BC goes from $68 \%$ to $29 \%$ (about 39\%) and $62 \%$ to $40 \%$ (22\%) for BS samples in the same range of temperature. The total decay is 2.5 times in IM and 1.8 times in $\mathrm{BC}$ with respect to $\mathrm{BS}$.

Interestingly, at $300^{\circ} \mathrm{C}$, the reflectance of all samples is the same, near $56 \%$. This can be understood considering that at this temperature, most of the goethite is being converted into hematite. For the three types of rocks, at higher temperature, the values of the reflectance differ due to the heating of organic material, which hides those effects due to the darkening of the material.

Our results for the reflectance can be contrasted with the effective porosity measurements (Figure 2). In the range of $25-300^{\circ} \mathrm{C}$, the effective porosity is nearly constant for the three types of rocks. IM is the most porous material than the other two types of samples for the complete range of temperatures, being around 3.6 times higher than $\mathrm{BS}$ and $\mathrm{BC}$ for temperatures lower than $300^{\circ} \mathrm{C}$. Temperature induce changes in the effective porosity, starting from $400^{\circ} \mathrm{C}$, in such a way that at $600^{\circ} \mathrm{C}$, the effective porosity is for IM 1.7, 1.3 times higher than BS and BC, respectively. Temperature induces significant porosity changes in IM samples which appear as large variations in diffuse reflectance. In contrast, BS and BC show smaller temperature-induced changes in porosity associated with smaller alterations in reflectance.

3.5. Colorimetry. The color $L^{*} a^{*} b^{*}$ values of natural and thermally treated limestones are shown in Figure 7 . The results for $L^{*}$ indicate that initially the rocks BC and IM are whiter (both around 75), but BS provides the lowest value, possibly due to its higher content of hematite inside of the calcareous matrix. However, $L^{*}$ values decrease when the temperature increases up to $600^{\circ} \mathrm{C}$, for $\mathrm{BC}$ and IM (Figure 7(a)), which means that the lightness diminishes and the surface becomes darker, by the presence of ashes of organic matter. On the other hand, BS exhibits smaller variations with temperature when compared with $\mathrm{BC}$ and IM samples.

The same behavior can be observed in $a^{*}$ chromaticity (red-green axis) (Figure 7(b)). The positive values of $a^{*}$ indicate that the surface of the rocks show a redness hue, where BS has the highest value (20.4), and IM (10.7) has the lowest. Additionally, at $300^{\circ} \mathrm{C}, \mathrm{BS}$ and $\mathrm{BC}$ exhibit a tendency towards more positive values of $a^{*}$, where the transition of goethite to hematite begins. The sample $\mathrm{BC}$ has the highest amount of goethite, and this growth can be associated with the conversion of goethite to hematite. Above $300^{\circ} \mathrm{C}$, the color changes to a darker shade of red in all the three types of rocks.

For $b^{*}$ chromaticity (blue-yellow axis), the behavior is different in comparison to $a^{*}$ and $L^{*}$, but is similar for the three rocks, showing a minimum at $400^{\circ} \mathrm{C}$ and maxima at $200^{\circ} \mathrm{C}$ and $500^{\circ} \mathrm{C}$ (Figure $7(\mathrm{c})$ ), which could be related to the transformation of organic matter and the presence of clays.

To facilitate the analysis of the effect of thermal treatments on the evolution of limestones color and compare with studies 


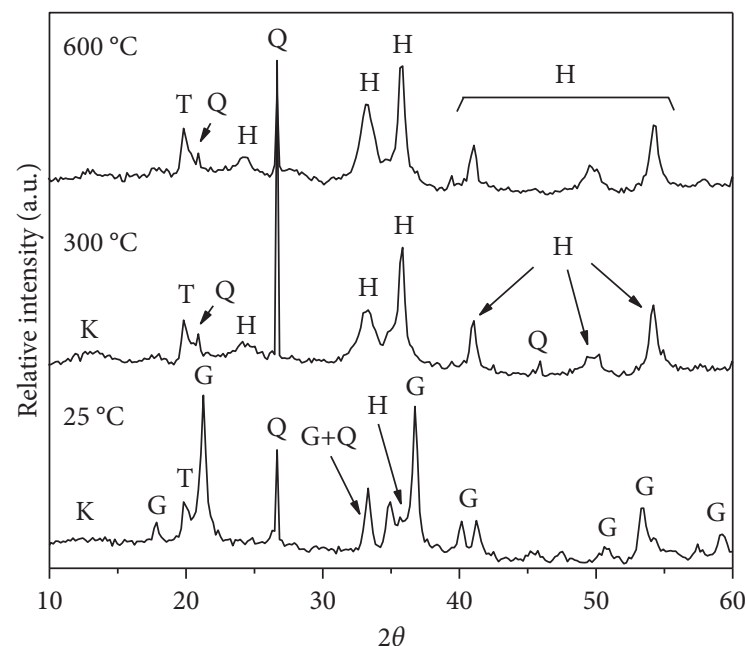

(a)

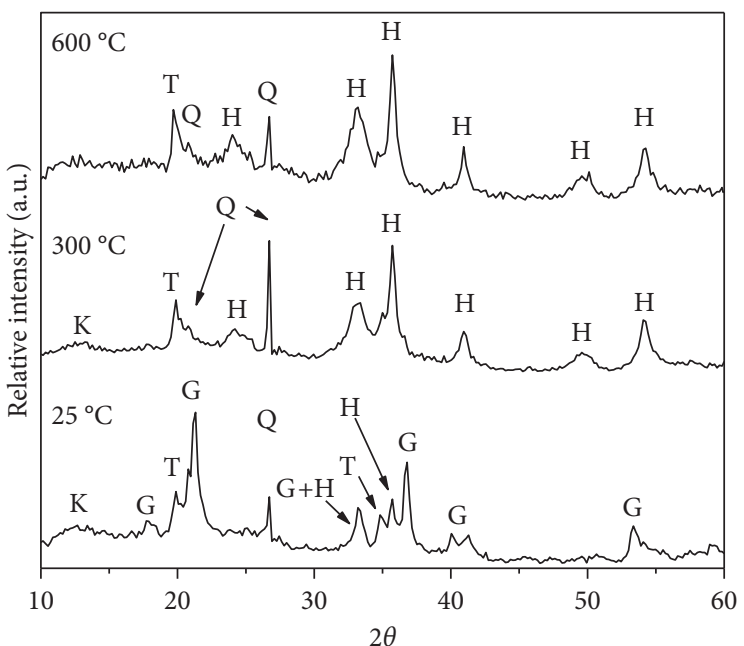

(b)

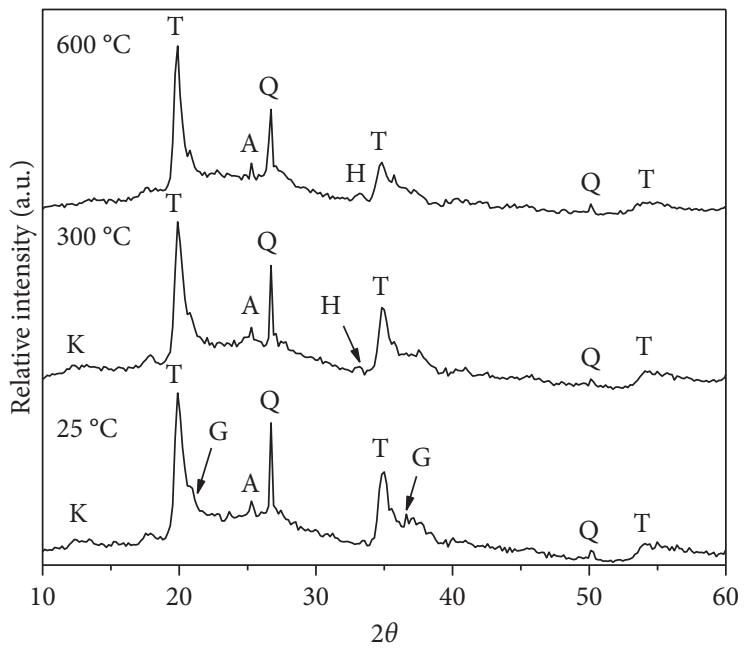

(c)

FIGURE 3: XRD patterns for the powders after the dissolution of calcium carbonate of the three types of limestones (a) biomicrite (BC-PAD), (b) biosparite (BS-PAD), and (c) intramicrite (IM-PAD) for thermal treatments of $25^{\circ} \mathrm{C}, 300^{\circ} \mathrm{C}$, and $600^{\circ} \mathrm{C}$. Reflection peaks are labeled as quartz $(\mathrm{Q})$, goethite $(\mathrm{G})$, hematite $(\mathrm{H})$, tosudite $(\mathrm{T})$, and kaolinite $(\mathrm{K})$.

using diverse characterization methodologies and color space representations, Table 2 provides the $L^{*} a^{*} b^{*}$ parameters CIE with their equivalent RGB color codes.

Summarizing, in our case, when limestones are subjects to different temperature conditions, as controlled increments, the samples showed two main significant changes. The first one corresponds to color changes attributed to the transformation of goethite into hematite and the second one to burning of organic materials, which forms ashes, but they can remain trapped darkening the surface. This is more remarkable for the case of IM, whose content of organic matter is $1.80 \%, 3.5$ times higher than BS and BC (containing around $0.52 \%$ ). Additionally, the thermal damage causes dilation of the rock, generating new microcracks that could produce partial evaporation of the burned organic matter and the increment of effective porosity.

It is important to note that the analysis of optical properties, using diffuse reflectance spectroscopy, can be helpful in the identification of iron minerals content, even if the particles of iron are scattered inside a heterogeneous calcareous matrix. This methodology can be helpful in identifying the hematite and goethite minerals and what type of rock has higher content of each type of oxide. Reflectance depends directly on the heterogeneous distribution of iron oxides inside the calcite matrix; besides clays such as kaolinite and tosudite, quartz and organic matter have a strong influence on the reflectance spectra.

These results can be understood based on the transformation occurring in the rocks, first of all on the dehydroxylation of goethite that transforms into hematite, which was observed in TGA curves at $275^{\circ} \mathrm{C}$, accompanied by the production of ashes from gradual burning of the organic matter, which can be retained up to $600^{\circ} \mathrm{C}$, that even at this temperature is not enough to volatilize it. It must also be considered that high concentrations of organic matter interfere, screening the observation of many minerals present in diffuse reflectance [23]. 


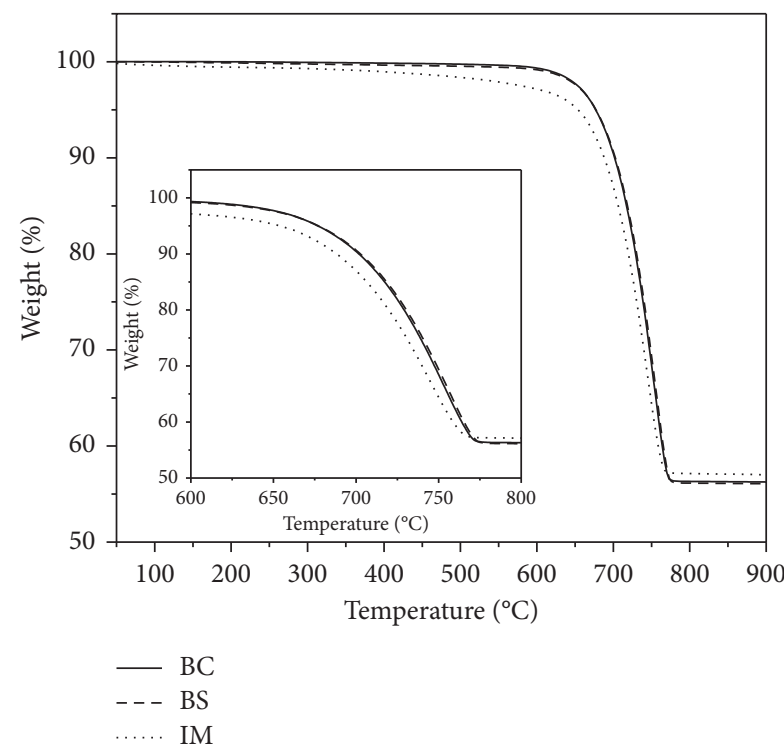

(a)

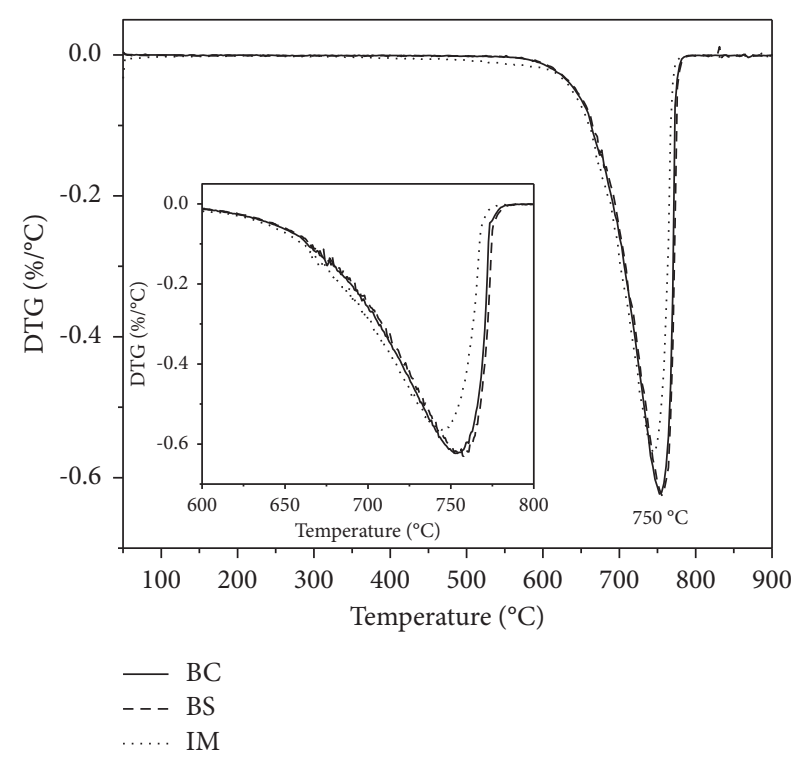

(b)

Figure 4: TGA curves of three untreated types of limestones. (a) TGA thermogram. (b) DTG curve.

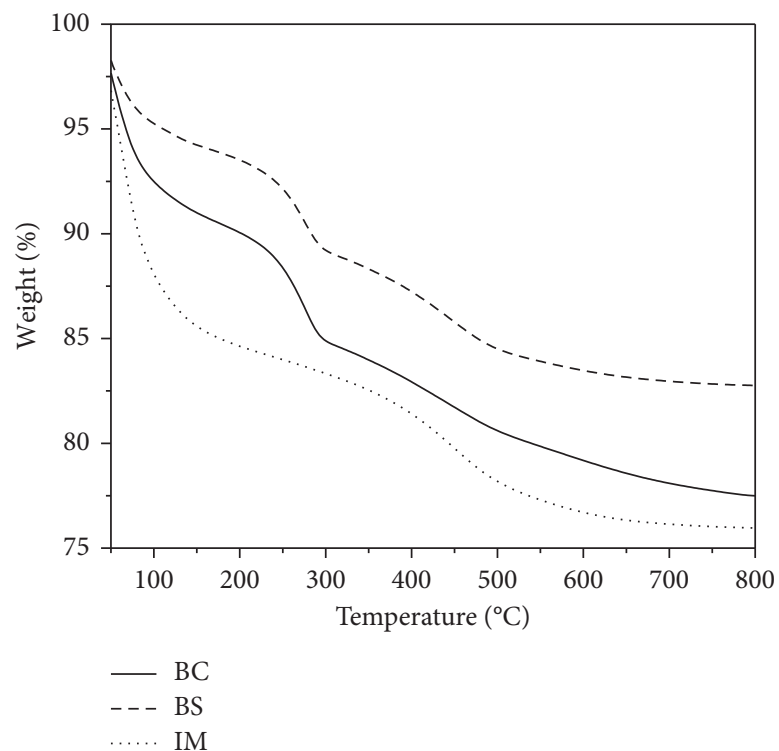

(a)

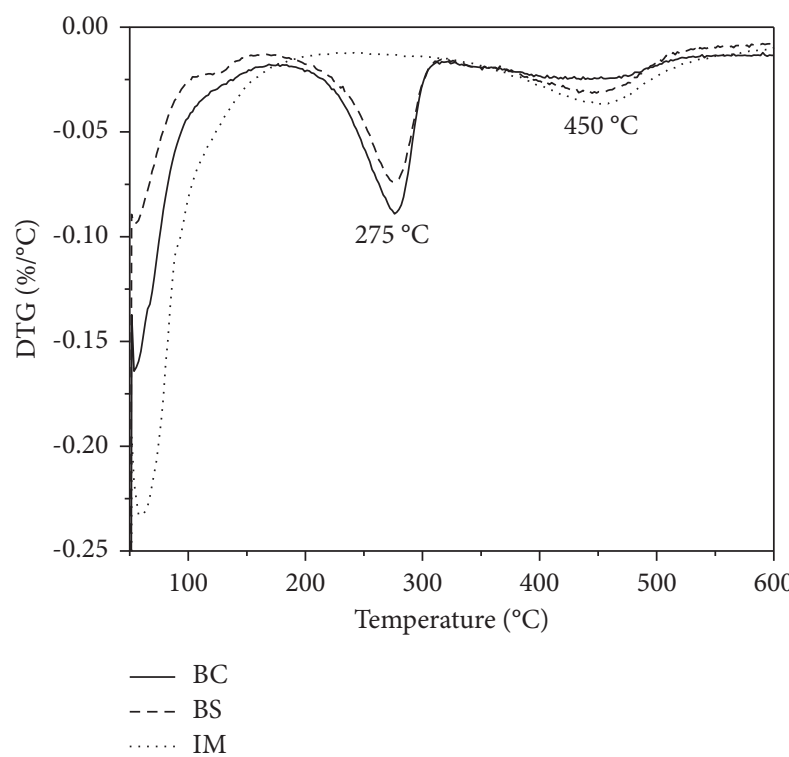

(b)

Figure 5: TGA measurements of the sample powders (PAD) for the three types of rocks. (a) TGA thermogram. (b) DTG curve.

Torrent et al. [36] determined that the characteristic color features of a rock can be affected by the presence of iron oxides, size and defects of crystals, shape, adsorbed impurities, and packing of particles, among others. A study by Yavuz et al. [12] associated the color change in carbonated rocks after $400^{\circ} \mathrm{C}$ to the elimination of organic matter along grain boundaries. In this study, samples BC and BS are most susceptible to the changes suffered by the mineralogical pigment of iron oxide; in contrast, IM shows changes mainly associated with pigments of organic matter.
Our results establish the basis to address the problem of using limestones of exposed lytic quarries for construction and restoration. For instance, in Yucatan Peninsula, an extended and common practice known as the "slash-and-burn" system is applied every year, during the dry period. The temperature which is reached in this traditional practice has a nonuniform pattern with high temperatures from $300^{\circ} \mathrm{C}$ to $700^{\circ} \mathrm{C}$ and even higher. Repeated burning and extreme heating lead to long-term cumulative thermal damage of the limestone integrity [37]. 


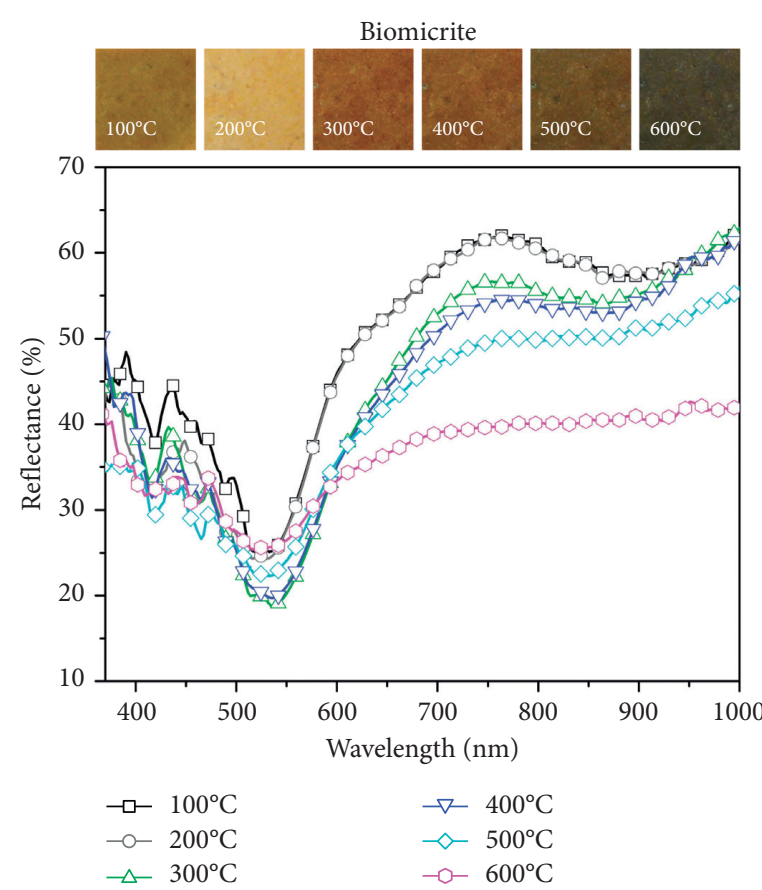

(a)

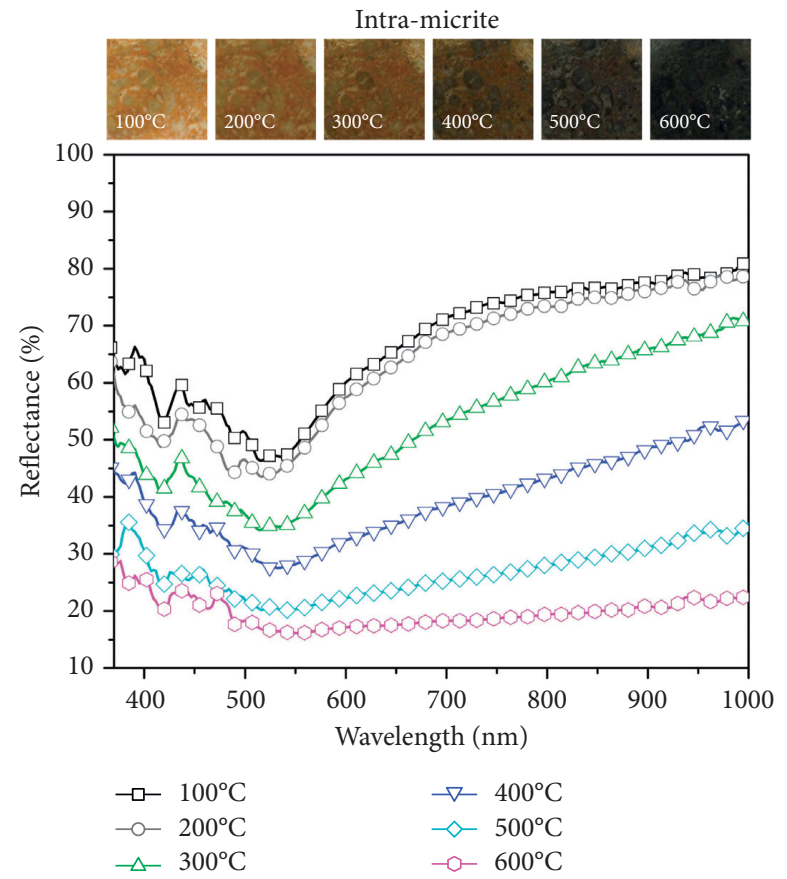

(c)

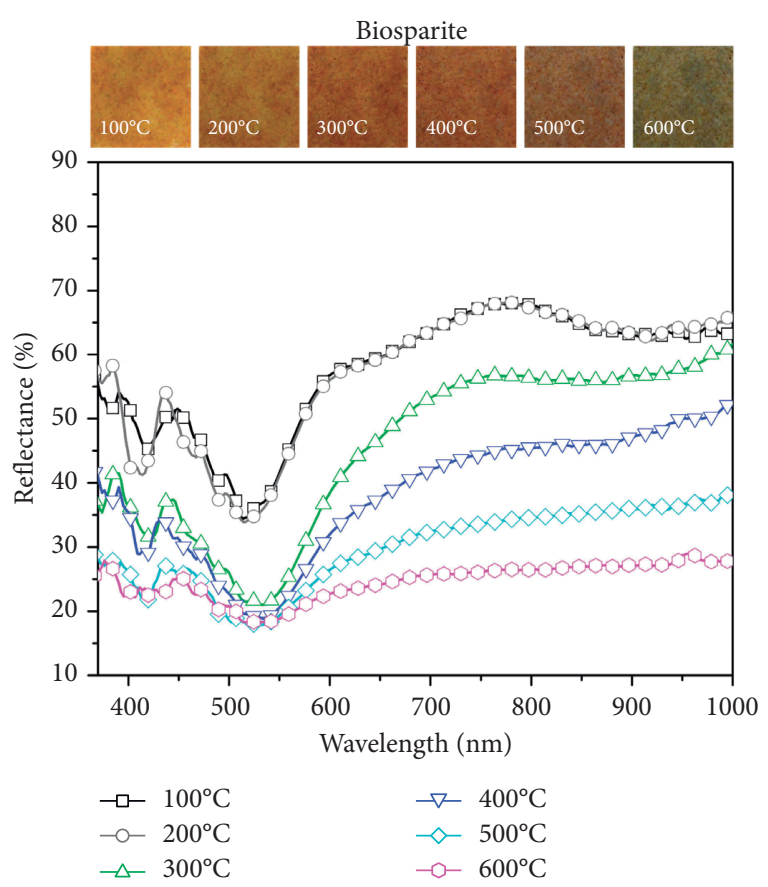

(b)

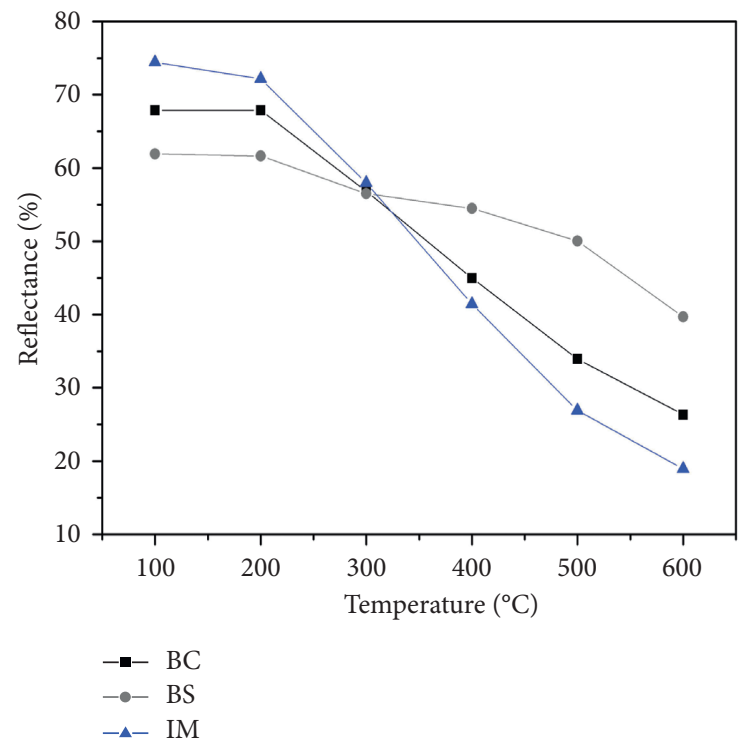

(d)

FiguRE 6: Diffuse reflectance spectra as a function of thermal treatment for limestone rocks: (a) BC, (b) BS, (c) IM, and (d) reflectance variation due to heating at a fixed wavelength of $765 \mathrm{~nm}$. The photographic images just give an illustrative guide of the optically observed changes induced by heating. 


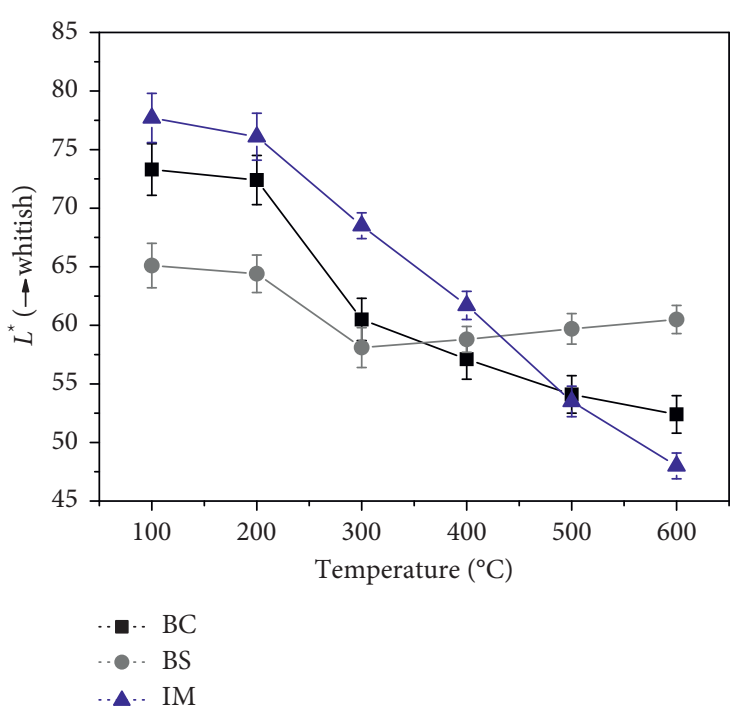

(a)

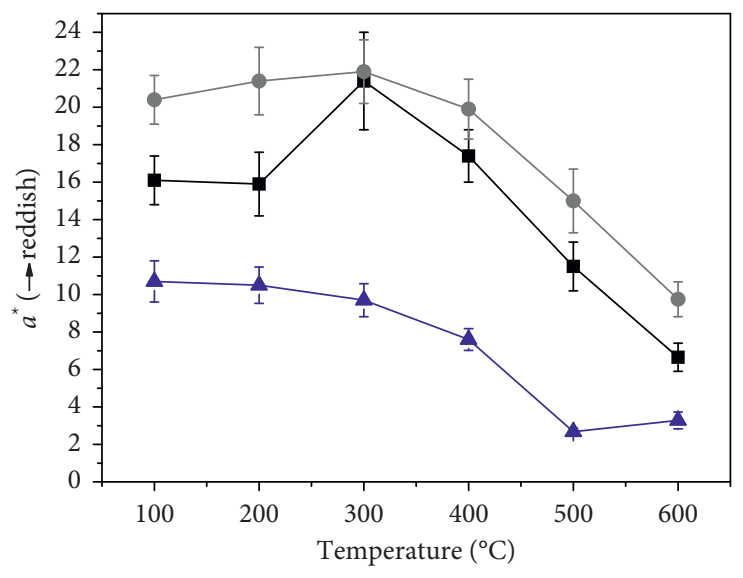

-.. BC

-.. BS

... IM

(b)

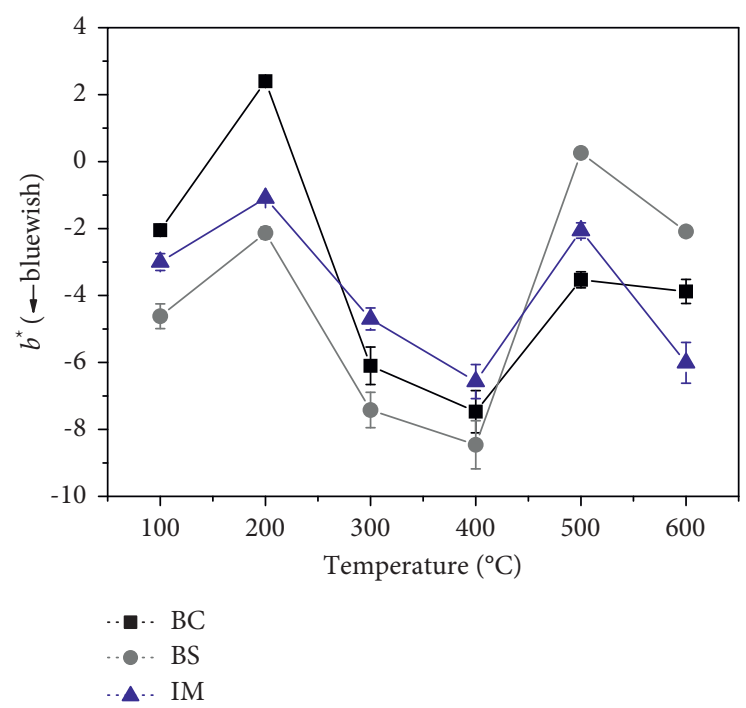

(c)

Figure 7: Variations of $L^{*} a^{*} b^{*}$ color values as a function of thermal treatment for three types of rocks: (a) $L^{*}$, (b) $a^{*}$, and (c) $b^{*}$.

TABLE 2: Conversion of $L^{*} a^{*} b^{*}$ space color to RGB color codes.

\begin{tabular}{lccccccc}
\hline Sample & Temperature $\left({ }^{\circ} \mathrm{C}\right)$ & $L^{*}$ & $a^{*}$ & $b^{*}$ & $R$ & $G$ \\
\hline BC & & 72 & 16 & -2 & 204 & 167 \\
BS & \multirow{2}{*}{100} & 65 & 20 & -5 & 189 & 145 \\
IM & & 77 & 11 & -3 & 208 & 181 \\
\hline BC & \multirow{2}{*}{300} & 60 & 21 & -6 & 176 & 187 \\
BS & & 57 & 21 & -7 & 168 & 196 \\
IM & & 70 & 10 & -5 & 186 & 124 \\
BC & 500 & 60 & 10 & -4 & 131 & 165 \\
BS & & 48 & 3 & -2 & 161 & 121 \\
IM & & & -6 & 114 & 139 \\
\hline
\end{tabular}




\section{Conclusions}

In this study, we have analyzed the influence of heating on the optical properties and color changes in three types of limestones in the range of relatively high temperatures from $100^{\circ} \mathrm{C}$ to $600^{\circ} \mathrm{C}$, in which the dominating crystalline structures of the limestones are not collapsing, preserving their heterogeneous calcareous nature. The transformations in the samples due to the temperature were analyzed by optical spectroscopy and correlated with porosity, crystalline structure, microscopic and optical images, and weight loss. The results have revealed that intramicrite shows the largest changes in reflectance, lightness $L^{*}$, and effective porosity, followed by biomicrite, being biosparite which experienced the smallest ones. We also find that the changes in color and reflectance are mainly associated, in this range of temperature, to dehydroxylation of goethite that transforms into hematite, as well as by the burning and partial release of the organic matter present in each type of rock. Our results can be helpful in determining the temperature at which the rocks were exposed and therefore if they are adequate for construction and restoration.

\section{Data Availability}

The data used to support the findings of this study are available from the corresponding author upon request.

\section{Conflicts of Interest}

The authors declare that they have no conflicts of interest.

\section{Acknowledgments}

This work was partially supported by CONACYT LAB2009-01 (123913) and FOMIX-Yucatán, 2008 (108160). The authors want to express their acknowledgement to M.Sc. J. Bante for his help in the optical assembling of the reflectance system and M.Sc. D. Aguilar in the characterization by XRD.

\section{Supplementary Materials}

Petrographic analysis and classification of the limestones and optical images of the surface of the limestone samples for different thermal treatment. . (Supplementary Materials)

\section{References}

[1] I. Rodríguez Pérez, G. Vasconcelos, P. B. Lourenço, P. Quintana, C. García, and A. Dionísio, "Physical-mechanical characterization of limestones from Yucatan churches, Mexico," Journal of Building Engineering, vol. 44, p. 102895 , 2021.

[2] O. Juárez-Rodríguez, D. Argote-Espino, M. Santos-Ramírez, and P. López-García, "Portable XRF analysis for the identification of raw materials of the Red Jaguar sculpture in Chichén Itzá, Mexico," Quaternary International, vol. 483, pp. 148-159, 2018.

[3] V. Martínez-Ibáñez, M. E. Garrido, C. Hidalgo Signes, and R. Tomás, "Micro and macro-structural effects of high temperatures in Prada limestone: key factors for future fireintervention protocols in Tres Ponts Tunnel (Spain)," Construction and Building Materials, vol. 286, p. 122960, 2021.

[4] E. Flûgel, Microfacies of Carbonate Rocks, Analysis, Interpretation and Application, Springer-Verlag Press, Heidelberg, Gemany, 2010.

[5] E. Martinho and A. Dionísio, "Assessment techniques for studying the effects of fire on stone materials: a literature review," International Journal of Architectural Heritage, vol. 14, no. 2, pp. 275-299, 2018.

[6] N. Kantiranis, A. Filippidis, B. Christaras, A. Tsirambides, and A. Kassoli-Fournaraki, "The role of organic matter of carbonate rocks in the reactivity of the produced quicklime," Materials and Structures, vol. 36, no. 2, pp. 135-138, 2003.

[7] M. Gómez-Heras, S. McCabe, B. J. Smith, and R. Fort, "Impacts of fire on stone-built heritage," Journal of Architectural Conservation, vol. 15, no. 2, pp. 47-58, 2009.

[8] F. Gherardi, J. Otero, R. Blakeley, and B. Colston, "Application of nanolimes for the consolidation of limestone from the medieval Bishop's Palace, Lincoln, UK," Studies in Conservation, vol. 65, 2020.

[9] A. Murru, D. M. Freire-Lista, R. Fort, M. J. Varas-Muriel, and P. Meloni, "Evaluation of post-thermal shock effects in Carrara marble and Santa Caterina di Pittinuri limestone," Construction and Building Materials, vol. 186, pp. 1200-1211, 2018.

[10] D. M. Freire-Lista, R. Fort, and M. J. Varas-Muriel, “Thermal stress-induced microcracking in building granite," Engineering Geology, vol. 206, no. 17, pp. 83-93, 2016.

[11] M. Hajpál, "Changes in sandstones of historical monuments exposed to fire or high temperature," Fire Technology, vol. 38, no. 4, pp. 373-382, 2002.

[12] H. Yavuz, S. Demirdag, and S. Caran, "Thermal effect on the physical properties of carbonate rocks," International Journal of Rock Mechanics and Mining Sciences, vol. 47, no. 1, pp. 94-103, 2010.

[13] W. S. González-Gómez, P. Quintana, A. May-Pat, F. Avilés, J. May-Crespo, and J. J. Alvarado-Gil, "Thermal effects on the physical properties of limestones from the Yucatan peninsula," International Journal of Rock Mechanics and Mining Sciences, vol. 75, no. 1, pp. 182-189, 2015.

[14] Z. Komponíková, M. Gómez-Heras, and J. Michňová, "Sandstone alterations triggered by fire-related temperatures," Environmental Earth Sciences, vol. 72, pp. 2569-2581, 2014.

[15] F. Zhang, J. Zhao, D. Hu, F. Skoczylas, and J. Shao, "Laboratory investigation on physical and mechanical properties of granite after heating and water-cooling treatment," Rock Mechanics and Rock Engineering, vol. 51, no. 3, pp. 677-694, 2018.

[16] Y. Shen, Y. Yang, G. Yang et al., "Damage characteristics and thermo-physical properties changes of limestone and sandstone during thermal treatment from $-30^{\circ} \mathrm{C}$ to $1000^{\circ} \mathrm{C}$, " Heat and Mass Transfer, vol. 54, no. 11, pp. 3389-3407, 2018.

[17] Z. Dong, Q. Sun, J. Ye, and W. Zhang, "Changes in color and roughness of red sandstone at high temperatures," Bulletin of Engineering Geology and the Environment, vol. 79, no. 4, pp. 1959-1966, 2020.

[18] Q. Sun, C. Lü, L. Cao, W. Li, J. Geng, and W. Zhang, "Thermal properties of sandstone after treatment at high temperature," International Journal of Rock Mechanics and Mining Sciences, vol. 85, pp. 60-66, 2016. 
[19] D. E. Sarici, "Thermal deterioration of marble: gloss, color changes," Construction and Building Materials, vol. 12, pp. 416-421, 2016.

[20] A. Dionísio, M. A. Sequeira Braga, and J. C. Waerenborgh, "Clay minerals and iron oxides-oxyhydroxides as fingerprints of firing effects in a limestone monument," Applied Clay Science, vol. 42, no. 1-2, pp. 629-638, 2009.

[21] J. Torrent and V. Barrón, "Diffuse reflectance spectroscopy of iron oxides," in Encyclopedia of Surface and Colloid Science, M. Dekker, Ed., CRC Press, New York, NY, USA, 2002.

[22] G. M. Da Costa, V. Barrón, C. Mendonça Ferreira, and J. Torrent, "The use of diffuse reflectance spectroscopy for the characterization of iron ores," Minerals Engineering, vol. 22, no. 14, pp. 1245-1250, 2009.

[23] L. S. Galvao and I. Vitorello, "Role of organic matter in obliterating the effects of iron on spectral reflectance and colour of Brazilian tropical soils," International Journal of Remote Sensing, vol. 19, no. 10, pp. 1969-1979, 1998.

[24] S. J. Gaffey, "Spectral reflectance of carbonate minerals in the visible and near infrared $(0.35-2.55 \mu \mathrm{m})$ : anhydrous carbonate minerals," Journal of Geophysical Research, vol. 92, no. B2, pp. 1429-1440, 1987.

[25] K. R. M. Adeline, C. Gomez, and N. Roger, "Predictive ability of soil properties to spectral degradation from laboratory VisNIR spectroscopy data," Geoderma, vol. 288, no. 15, pp. 143-153, 2017.

[26] G. Zheng, D. Ryu, C. Jiao, and C. Hong, "Estimation of organic matter content in Coastal soil using Reflectance Spectroscopy," Pedosphere, vol. 26, no. 1, pp. 130-136, 2016.

[27] D. Benavente, F. Martínez-Verdú, A. Bernabeu et al., "Influence of surface roughness on color changes in building stones," Color Research \& Application, vol. 28, no. 5, pp. 343-351, 2003.

[28] F. Bardelli, G. Giuli, and F. Di Benedetto, "Spectroscopy study of volcans ashes," Journal of Hazardous Materials, vol. 400, no. 5, p. 123231, 2020.

[29] W. Zhou, L. Chen, and M. Zhou, "Thermal identification of goethite in soils and sediments by diffuse reflectance spectroscopy," Geoderma, vol. 155, no. 1-2, pp. 419-425, 2010.

[30] M. Elias, C. Chartier, G. Prévot, H. Garay, and C. Vignaud, "The colour of ochres explained by their composition," Materials Science and Engineering: B, vol. 127, no. 1, pp. 7080, 2006.

[31] International Society for Rock Mechanics, Rock Characterization, Testing and Monitoring: ISRM Suggested Methods, E. T. Brown, Ed., Pergamon Press, Oxford, UK, 1981.

[32] J. M. Martínez, J. A. Galantini, M. E. Duval, F. M. López, and J. O. Iglesias, "Estimating soil organic carbon in Mollisols and its particle-size fractions by loss-on-ignition in the semiarid and semihumid Argentinean Pampas," Geoderma Regional, vol. 12, pp. 49-55, 2018.

[33] Y. Zhang, Q. Sun, and J. Geng, "Microstructural characterization of limestone exposed to heat with XRD, SEM and TGDSC," Materials Characterization, vol. 134, pp. 285-295, 2017.

[34] H. Liu, T. Chen, X. Zou, C. Qing, and R. L. Frost, "Thermal treatment of natural goethite: thermal transformation and physical properties," Thermochimica Acta, vol. 568, pp. 115121, 2013.

[35] N. Bouzidi, A. Siham, N. Concha-Lozano et al., "Effect of chemico-mineralogical composition on color of natural and calcined kaolins," Color Research \& Application, vol. 39, no. 5, pp. 499-505, 2014.

[36] J. Torrent and V. Barrón, "Diffuse reflectance spectroscopy," in Methods of Soils Analysis Part 5. Mineralogical Methods,
A. L. Ulery and L. R. Drees, Eds., Soil Science Society of America, Madison, WA, USA, 2008.

[37] B. B. Faust, A. Anaya-Hernández, and H. G. Acuña, "Reclaiming the past to respond climate change: mayan farmers and ancient agricultural techniques in the Yucatan Peninsula of Mexico," in Climate Change and Threatened Communities: Vulnerability, Capacity, and Action, A. P. Castro, D. Taylor, and D. W. Brokensha, Eds., Rugby; Practical Action Press, Warwickshire, UK, 2012. 